Rocking My Life Away 


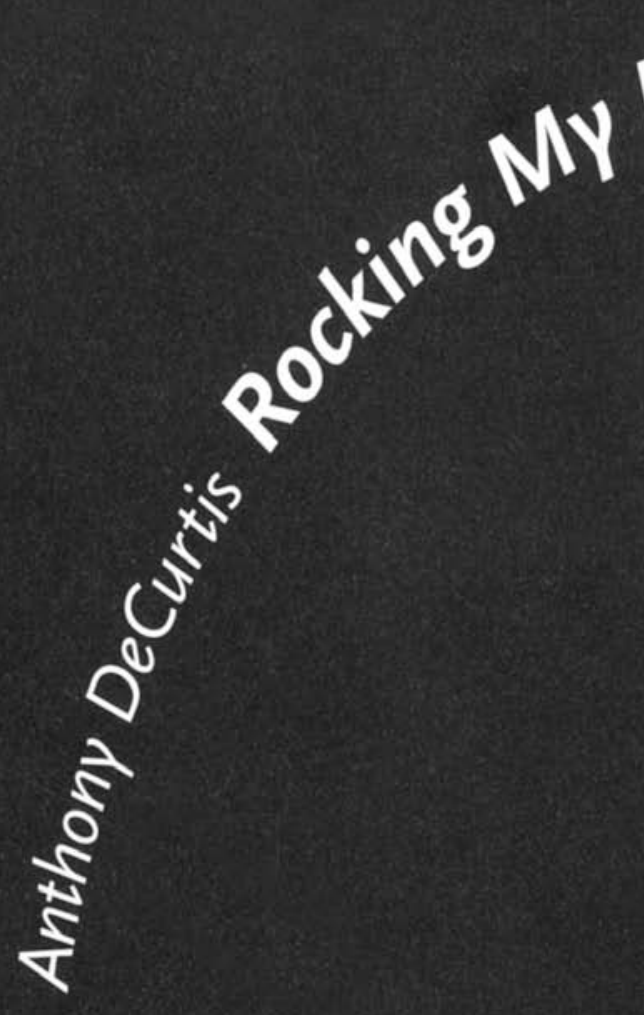

Duke University Press

Durham and London 


\section{Writing about}

\section{Music and Other Matters}

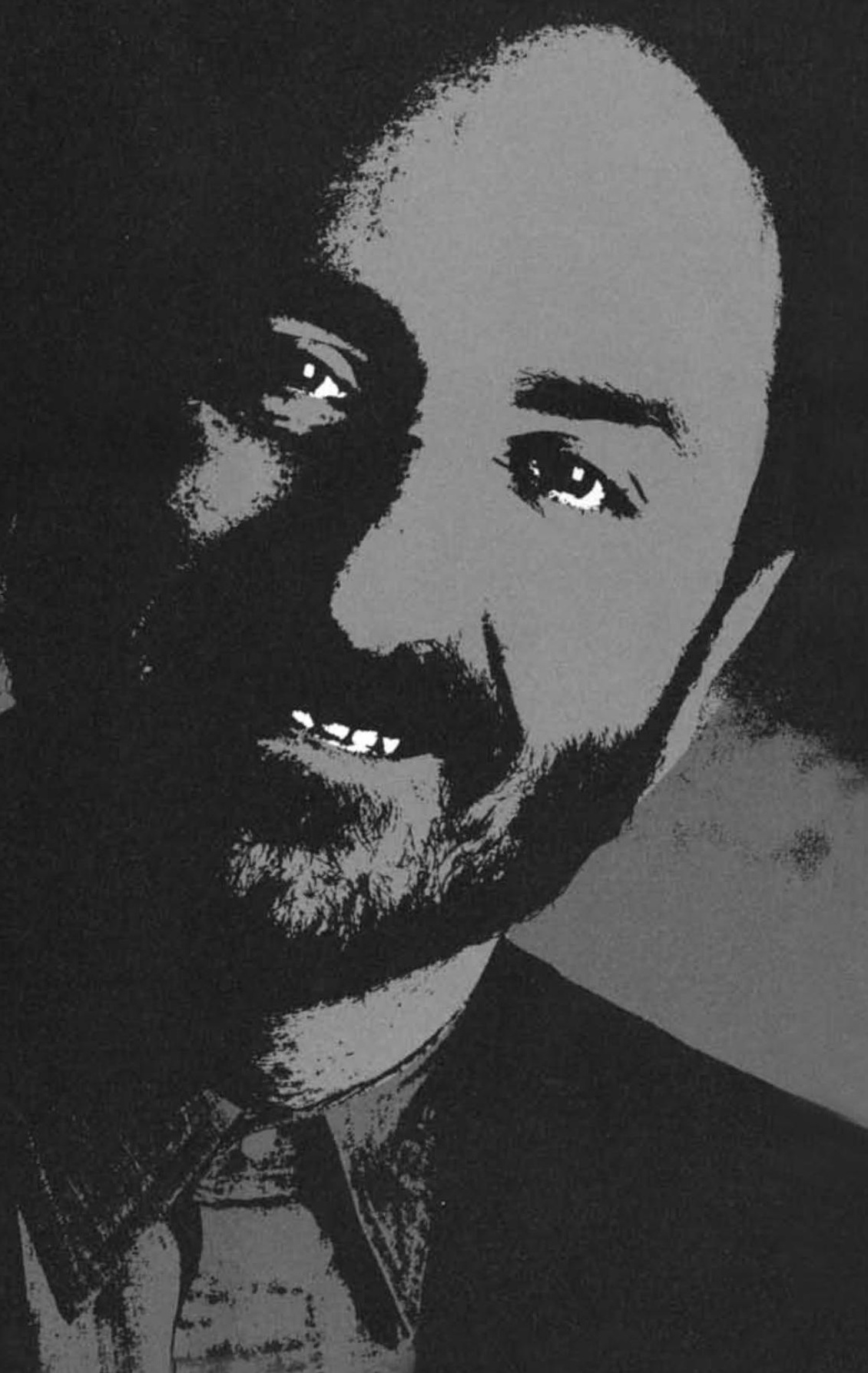


(C) 1998 Anthony DeCurtis

First printing in paperback, 1999

All rights resenved Printed in the United States of America on acid-free paper $\infty$ Designed by Cherie Westmoreland

Typeset in Scala and Scala Sans by Keystone Typesetting, Inc.

Library of Congress Cataloging-in-Publication Data appear on the last printed page of this book. 
For Rose Marie and Renato DeCurtis,

who would have glowed with pride to see it, and for Dom and Carmela, who made me the person who could write it, with my deepest love and gratitude 
